\title{
Best Practices Framework for Online Faculty Professional Development: A Delphi Study
}

\author{
Sandra Coswatte Mohr \\ New England College of Optometry \\ Kaye Shelton \\ Lamar University
}

\begin{abstract}
Online learning is now a common practice in higher education. Because of the continued online enrollment growth, higher educational institutions must prepare faculty throughout their teaching career for learning theory, technical expertise, and pedagogical shifts for teaching in the online environment. This study presents best practices for professional development for faculty teaching online. In this study, the Delphi Method was used to gain consensus from a panel of experts on the essentiality of professional development items to help faculty prepare for teaching in the online environment. After four survey rounds to develop consensus, best practices were identified consisting of essential professional development and institutional/organizational strategies for supporting faculty teaching online. These results are significant for planning new or improving existing faculty development programs that enhance teaching and learning in the online classroom.
\end{abstract}

Keywords: online faculty development, online faculty training, teaching online

Mohr, S., \& Shelton, K. (2017). Best practices framework for online faculty professional development: A Delphi study. Online Learning, 21(4), 123-140. doi: 10.24059/olj.v21i4.1273

\section{Best Practices Framework for Online Faculty Professional Development: A Delphi Study}

Technology has forever changed the higher education landscape through enriched learning environments; because of this, faculty need tools and resources to help successfully facilitate learning in online educational environments (Facer, 2011). Today, online education enrollment continues to grow even in the face of declining overall higher education enrollment (Allen \& Seaman, 2016, 2017) with over 6 million students taking at least one online course in Fall 2015 (Allen \& Seaman, 2017). In fact, one-third of all students in higher education are now enrolled in at least one online class and about half of those students complete all of their classes at a distance (Allen \& Seaman, 2017). 
Because of the continued growth of online education, faculty professional development has become a major focus (Herman, 2012), as faculty members often teach as they were taught, and many distance educators did not take online courses as students, which leaves them without a benchmark model for online teaching (Schmidt, Tschida, \& Hodge, 2016). Given that faculty members are subject matter experts in the classroom, without professional development, they may not be creating the most effective learning environments for students (Meskill \& Anthony, 2007). As institutions adopt online education to support institutional growth and student needs, it becomes essential to provide faculty with effective professional development opportunities that expose them to online methodologies (Vaill \& Testori, 2012).

Higher educational leaders need to build and foster a common vision around the role of online teaching within an institution so that it can be integrated into the faculty and campus culture (Kaminskaya, 2006). Unfortunately, most professional development for faculty has been ineffective and wasteful more times than not because it has often been ad hoc, discontinuous, and unconnected to any plan for change (Reeves, 2012). In addition, many professional development opportunities for online faculty focus around technological training, but online instructors would also like the opportunity to learn about effective online pedagogical practices (Bailey \& Card, 2009). Further, professional development opportunities are essential for faculty to learn from best practices and develop successful facilitation skills within an online environment (Moskal, Thompson, \& Futch, 2015).

Based on a review of the literature of centers for teaching and learning, online faculty training, and faculty professional development, consistent standards have not been developed to help those responsible preparing faculty for the online environment such as centers for teaching and learning. Further, an abundance of technology tools and resources are available for the online modality, but best practices for faculty development and use of these tools and resources have not been created (Tabor, 2007). Using technology has become ubiquitous at most higher education institutions and faculty need professional development opportunities to help them understand when to use technology and to what degree to use technology in the online learning process (Ouellett, 2010). Because the availability of technologies continues to increase, so has the need for faculty development for using technology as a tool in the online learning environment (Picciano, 2006). With this in mind, higher education institutions need to prepare faculty throughout their teaching career for learning theory, technical expertise, and pedagogical shifts before and as they teach in the online environment (Shelton, Saltsman, Hostrom, \& Pedersen, 2014). In addition to the training and teaching components, faculty need support and training in all aspects that interact with the online program (Shelton \& Saltsman, 2005). Therefore, the purpose of this study was to identify best practices for providing professional development for faculty teaching online.

\section{Review of Related Literature}

Institutions need to create professional development opportunities that support faculty transitioning into online teaching to help ensure quality (Schmidt et al., 2013). Key professional development practices that enable faculty to develop their online role include visibility, intentionality, and active engagement (Jaggars, Edgecomb, \& Stacey, 2013). Successful faculty development programs provide opportunities to build upon previous learning activities, collaborate with peers, and align with state and national standards (Birman, Desimone, Porter, \& Garet, 2000). To date, research suggests development programs are most effective when they 
incorporate diverse teaching methods, experiential learning, effective peer and colleague relationships, provide feedback, and apply effective teaching and learning principles (Steinert et al., 2006). Ideally, teaching practices should help faculty identify, access, and use information in several contexts to assist student learning (Otto, 2014). Additionally, faculty development programs need to recognize faculty members' experiences as learners and teachers in the classroom to build upon those experiences and continue growing their knowledge (McQuiggan, 2011).

A critical component of successful online programs is the preparation of faculty to teach online (Baran \& Correia, 2014; Kerrick, Miller, \& Ziegler, 2015). In addition, faculty professional development should provide faculty with the skills needed to produce quality-learning experiences for their students (Wei, Darling-Hammond, Andree, Richardson, \& Orphanos, 2009), as many faculty feel they can teach the same online as they do face-to-face (Hale, 2012). Moreover, faculty members are adult learners who should be continuously working through a process of critical reflection and action to transform meaning of structures related to online teaching (Baran, Correia, \& Thompson, 2011). In addition, professional development opportunities can help faculty feel less isolated and disconnected from colleagues, build a community of learners, improve teaching, and help to build organizational capacity (Eib \& Miller, 2006). However, most new online instructors begin teaching with little to no training or preparation specific to the online classroom (AlexiouRay \& Bently, 2015; Fish \& Wickersham, 2009). Additionally, online faculty often have little training in pedagogy for online instruction (Gabriel \& Kaufield, 2008) and may not have an interest in learning more about pedagogy (Major, 2010). Additionally, faculty members may find it challenging to be placed in the student role and making mistakes in a place where one cannot lose face (Kress, Thering, Lalonde, Kim, \& Cleeton, 2012). It is not uncommon for faculty to seem resistant to change or even dismiss the efforts of others who are engaged and demonstrating value in technological advancements (Kress et al., 2012).

Lane (2013) suggested that most professional development opportunities are too limited for faculty who are learning to teach online because they focus more on technology and not pedagogy (Lane, 2013). As online education has been growing, faculty involvement and acceptance of online education has been modest and limited change has occurred with online pedagogy (Natriello, 2005; Stewart, Bachman, \& Johnson, 2010). In addition, an absence of faculty training in online pedagogy leads to low levels of faculty participation as well as poorly designed and executed online courses, which then may lead to lower student success and faculty satisfaction (University Leadership Council, 2010). However, support for professional development around online education is critical to allow faculty the opportunity for pedagogical problem solving and discovery (Kreber \& Kanuka, 2006).

\section{Purpose Statement and Research Questions}

The purpose of this research was to identify best practices for higher education teaching and learning centers. This research study sought to bring consensus among directors of teaching and learning centers and directors of online learning to identify best practices of faculty development about online learning using the Delphi Method. While many schools use different faculty development practices, little is known about which faculty development practices are seen as the most effective and efficient (Austin \& Sorcinelli, 2013). Before starting and providing resources for an online education at a teaching and learning center, it is important to understand which types of programs will be most effective and appropriate for their institutional contexts (Herman, 2012). Further, conducting research to assess the needs of faculty is an essential first 
step to develop an effective staff development plan (Engleberg, 1991). Thus, this research study provided a way to help understand learning needs and ways to invest in faculty development based on a needs assessment (Witkin, 1984). The following research question was analyzed for this study: What are best practices for offering professional development for higher education online faculty?

\section{Methods}

The Delphi Method, a procedure designed to have a panel of experts reach consensus on a particular topic without face-to-face interaction, was used to gather consensus from an expert panel. The method is cost-effective and collects and quantifies a large amount of data (Linstone \& Turoff, 1975). Originating in the 1950s, the Delphi Method was created through a series of studies that the RAND Corporation conducted with the objective of developing a technique to obtain the most reliable consensus of a group of experts (Dalkey \& Helmer, 1963). The Delphi Method incorporates qualitative data collection through expert opinions to achieve consensus while relying on quantitative techniques to rank the areas related to the issue (Pchenitchnaia, 2007). Linstone and Turoff (1995) identified four important phases of this method. Phase one begins with exploration of the research topic where each panel expert responds to provided prompts as well as contributes additional information on the topic being explored. Phase two is the process of gaining consensus among the panel experts. Phase three is where the reasoning behind disagreement is extracted and digested. Finally, the fourth phase ends when all previously gathered information has been analyzed and evaluations have been returned to panel experts for consideration.

Delphi Method. According to Rowe and Wright (1999), four key features characterize the Delphi Method:

1. Anonymity of participant allows free expression of opinions without influence of groupthink.

2. Iterative process where participants refine their views each round based on participant feedback.

3. Controlled feedback that allows for participants to clarify or change their views during each iterative round.

4. Data allows for quantitative analysis and interpretation.

The Delphi Method was selected to generate consensus from the expert panel and examine informed judgments on a topic spanning a wide range of disciplines (Delbecq, Van de Ven, \& Gustafson, 1975). The research method was selected because there was incomplete knowledge around best practices for training and development of online faculty in teaching and learning centers. Further, the goal of the method was to improve the understanding around problems, opportunities, and solutions and identify best practices that can be used in teaching and learning centers to prepare faculty for the online classroom (Skulmoski, Hartman, \& Krahn, 2007). The first-round survey used in this Delphi study was developed from a review of literature of professional development for online faculty members.

Expert panel. In a Delphi study, the participant sample consists of the respondents on a panel of experts on the topic needing consensus (Wilhelm, 2001). For this study, the expert panel consisted of Directors of Teaching and Learning Centers and Directors of Online Learning Departments that support online programs at their higher education institutions in the United 
States. Directors of Online Learning Departments were included since many institutions offer professional development through these departments. Members of the Professional and Organization Development Network in Higher Education (POD) and members of the Online Learning Consortium (OLC) were identified as potential panel members. In addition, snowball sampling was used to identify additional Directors of Online Learning. Further, the panel criteria for selection included a minimum of five years' experience working in a teaching and learning center or online program in higher education or a role in supporting faculty at an institution that teaches online. Experience working with online faculty for at least five years supports the knowledge necessary to offer expert opinion.

Careful attention was given to select expert panel participants who had knowledge and strong experience in training online faculty (Baker, Lovell, \& Harris, 2006). The potential panel experts were selected for this study because of their knowledge of online education or involvement with teaching and learning centers along with the desire to potentially benefit from the results of this study. Eighty prospective panel members were identified as meeting the criteria for this study and were solicited for study participation. Fifty-seven experts agreed to participate.

For this study, finding participants with a background in online education and teaching and learning centers was essential. The majority of panel experts $(59.5 \%)$ had experience in both online education and teaching and learning centers and $38 \%$ had experience in online education with only $2 \%$ having sole experience in teaching and learning centers. There was also a good distribution of institutional experience from the panel experts with $50 \%$ being at public universities followed by $29 \%$ of panel experts from private colleges or universities. The participant sample consisted of Directors of Teaching and Learning Centers from the Professional and Organizational Development Network (POD) and Directors of Online Programs from the Online Learning Consortium's Institute for Engaged Leadership in Online Education Alumni group. POD is the largest and oldest faculty development organization and the Online Learning Consortium is the leading organization dedicated to supporting quality online education. It is important to note that more than $57 \%$ of the expert panel had 15 or more years' experience in online education or teaching and learning centers as the strength of the Delphi Study is related to the expertise level of the panel members.

Table 1 provides the percentage participation of the members of the expert panel for each round. Among the original panel members, $72 \%$ completed all rounds of the Delphi survey process. As confirmed in the literature, it is difficult to keep a panel of experts fully engaged through the survey process. However, the participation rate for this study was above the $70 \%$ per round rate recommended by Hasson, Keeney, and Mckenna (2000). Given the large time commitment of panel experts, non-response rates can be an issue (Linstone \& Turoff, 1975); therefore, precautions were taken to encourage full participation. The actions included clearly defining the time commitment, providing a financial incentive, and offering to share the research results with the experts. In order to encourage a high response rate, panel experts who completed all rounds of the Delphi research received a monetary honorarium of a \$25 U.S. dollar Amazon gift card provided by the researcher. 


\begin{tabular}{cccc}
\hline Delphi Round & Experts Enlisted & Completed Survey & Response Rate \\
\hline I & 57 & 54 & $94.7 \%$ \\
II & 54 & 42 & $77.9 \%$ \\
III & 42 & 39 & $92.9 \%$ \\
IV & 39 & 39 & $100 \%$ \\
\hline
\end{tabular}

Table 1. Percentage of Expert Panel Participation for Each Round

Delphi survey rounds and analysis. During each round of this study, panel experts responded to each survey item using a six-point balanced bipolar, Likert scale response (Likert, 1932). The panel experts were asked to evaluate the current and future essentiality of each suggested component of online faculty development elements where a score of -3 was Definitely Not Essential, -2 was Not Essential, -1 was Slightly Not Essential, 1 was Slightly Essential, 2 was Essential, 3 was Definitely Essential. There was also an option for the panel member to respond that they do not have the experience to provide an expert opinion on this item. Using a negative scale is common in Likert scale implementation and helps when analyzing data to indicate the strength of agreement or disagreement (Peabody, 1962).

The desired outcome in Delphi research is for creativity, synergy, and consensus to occur with the panel experts (Rotondi \& Gustafson, 1996). The survey procedure comes to an end when consensus or stability of responses is achieved (Murry \& Hammons, 1995). The Delphi panel experts were asked if they wanted to change or keep their rank for each survey item based on the group responses. In this study, if consensus on a variable was not reached after three survey rounds, it was concluded that consensus was not reached, and the item was removed.

After Institutional Review Board approval, recruitment began for potential panel participants of the opportunity to participate in this research study. An email was sent that explained the topic of research, gave information about the Delphi Method, estimated the time commitment for participation, and the included the request to participant. The Delphi process started with a survey of literature of professional development practices, which focused on the research question (Skulmoski et al., 2007). From the literature review, the first survey round questions provided the panel quality standards of teaching and learning and faculty support established from the Online Learning Consortium's Quality Scorecard Handbook (Shelton et al., 2014). The initial survey concluded with questions that were open-ended to allow participants to provide a broad range of responses that were then used to build the collective perspective of the research participants on the topic (Linstone \& Turloff, 1975). The online questionnaire was electronically distributed to Delphi participants and was returned online for data analysis. Based on the round one data, quantitative analysis reviewed descriptive statistics and mean scores for consensus and qualitative coding was used to help categorize the new responses provided by the panel members to prepare for the second survey round.

For this research, the goal was to establish consensus among the expert panel (Linstone \& Turoff, 1995). This study used descriptive statistics to measure the consensus level established with a mean score of 2.0, which equated to "Essential" out of the 3.0 maximum value response option used for measurement. After analyzing results of each round, any item that met consensus was removed from consideration in subsequent rounds. The survey items that had not met consensus were returned to the panel experts for further review along with the percentage of agreement among the prior round of responses. 
The first-round survey provided from the literature 59 professional development considerations, 12 organizational/institutional best practices, and 12 online classroom contextual best practices for a total of 83 items for the panel to review. In the first survey round, the expert panel suggested an additional 29 professional development considerations, 22 organizational/institutional best practices, and 7 online classroom contextual best practices that were then added to the second survey (a total of 58 suggestions). A total 47 items met the consensus level and were removed from consideration (see Table 3 for complete round by round results).

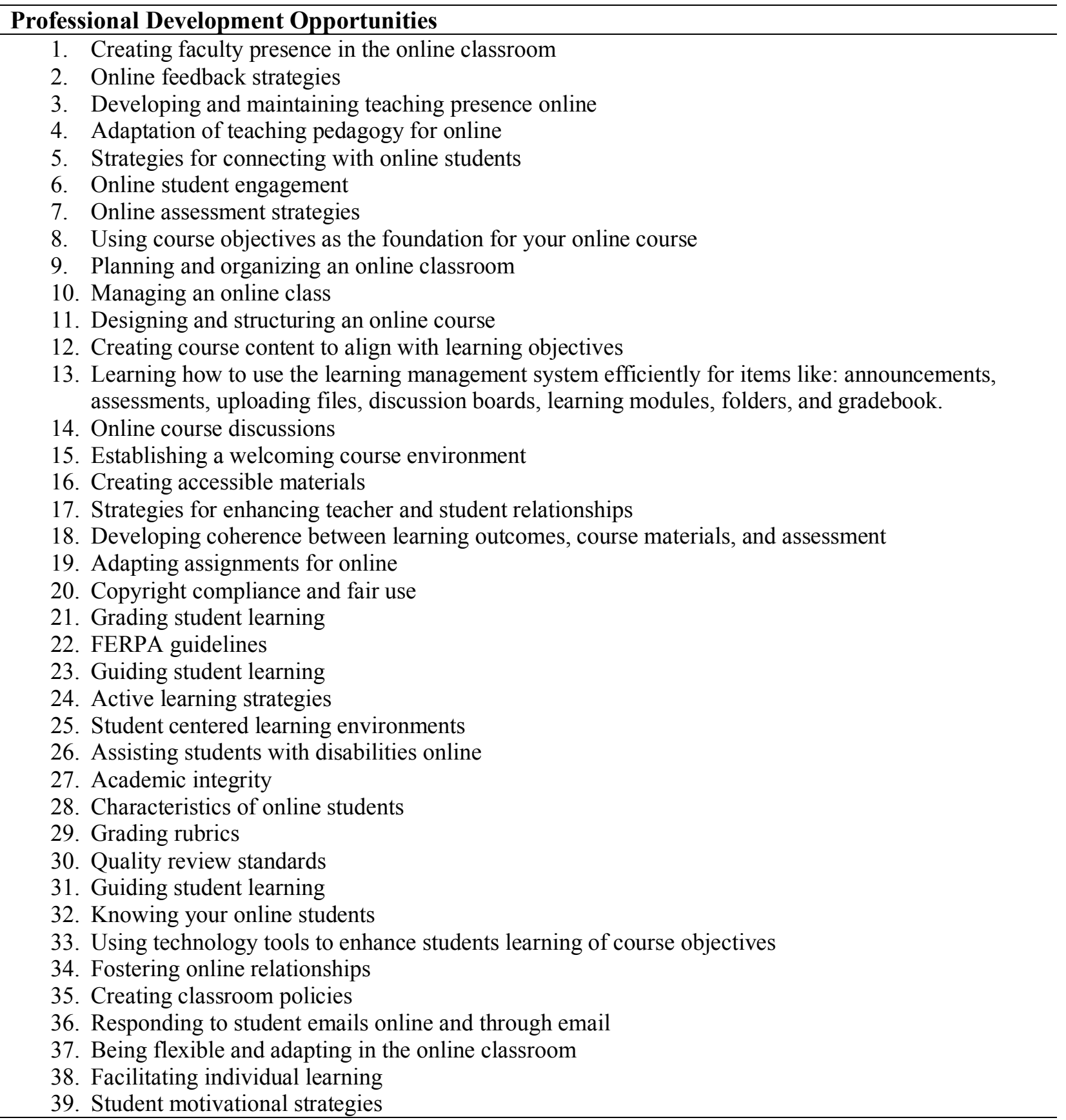

\section{Table 2. Round 1 Survey Items}


40. Facilitating group learning (collaboration)

41. Holding online office hours

42. Applying evidence based teaching in the online classroom

43. Integrating multimedia tools in the online classroom

44. Evaluating an online course

45. Pedagogical knowledge about technology integration

46. Introduction to instructional design

47. Faculty classroom/time management strategies

48. Creating innovating learning opportunities in the online classroom

49. Technology basics - Email and Microsoft Office products

50. Technology basics - Screen-casting tools

51. Retention strategies

52. Adult learning theories

53. Technology basics -Video creation tools

54. Teaching strategies for a generational diverse classroom

55. Technology basics -Audio tools (podcasting)

56. Strategies to support lifelong learning

57. Supporting military learners

58. Learning through social media and networking tools

59. Career focused learning

\section{Organizational Development Opportunities}

60. Support from instructional designers/technologists

61. Support from technology department on audio/visual resources

62. Polices on intellectual ownership

63. Higher education institution specific training for online

64. Meeting Institute-specific academic standards

65. Faculty mentoring

66. Support from library resources

67. Creating a strong school culture for online teaching

68. Institutional demographics of online students

69. Peer support programs

70. Participating in a community of practice in faculty content areas

71. Reward system for good online teaching

\section{Contextual Development Opportunities}

72. Faculty support for instructional design

73. Faculty support for technology

74. Strong orientation system for faculty that includes best practice resources and course design templates

75. Understanding how to use technology

76. Evaluating online classes: Student evaluation

77. Faculty support for selecting technology

78. Troubleshooting issues when they arise in the online environment

79. Evaluating online classes: Faculty evaluation

80. Evaluating online classes: Organizational evaluation

81. Faculty motivational strategies

82. Using goal setting in creating a faculty professional development plan

83. Strategies for supporting lifelong learning

Table 2 (cont.). Round 1 Survey Items 
For the second survey, in addition to the 58 new suggestions, 36 items were returned that did not meet consensus for a re-vote. After the second survey round, a total of 14 items reached consensus. Following the same process from round one, the round three questionnaire was developed based on the prior responses. The third survey round resulted in seven items reaching consensus. The fourth survey round returned those items not reaching consensus, but all failed to achieve consensus. Each round of survey questions became more focused based on the data analysis and research questions. Table 3 provides an overall summary of each survey round.

\begin{tabular}{cccccc}
\hline & $\begin{array}{c}\text { Professional } \\
\text { Development } \\
\text { Items with } \\
\text { Consensus }\end{array}$ & $\begin{array}{c}\text { Organizational/Institutional } \\
\text { Items with Consensus }\end{array}$ & $\begin{array}{c}\text { Online } \\
\text { Classroom } \\
\text { Contextual } \\
\text { Items with } \\
\text { Consensus }\end{array}$ & $\begin{array}{c}\text { Total } \\
\text { Items } \\
\text { Achieving } \\
\text { Consensus }\end{array}$ & $\begin{array}{c}\text { Original } \\
\text { Survey } \\
\text { Items/Panel } \\
\text { Suggestions }\end{array}$ \\
\hline $\begin{array}{c}\text { Round } \\
\text { I } \\
\text { Round } \\
\text { II } \\
\text { Round } \\
\text { III } \\
\text { Round } \\
\text { IV }\end{array}$ & 32 & 7 & 8 & 47 & $47 / 0$ \\
& 5 & 8 & 2 & 14 & $2 / 12$ \\
\hline
\end{tabular}

Table 3. Survey Round Data Collection Summary

\section{Limitations}

Research limitations are potential weaknesses in the study or things that are beyond researcher control (Creswell, 2014). For this study, the following limitations exist:

1. Potential research bias can influence the qualitative responses.

2. Researcher error in execution can occur in returning new responses to the panel suggested in prior rounds.

3. Because the Delphi Method requires several surveys, the expert panel may grow weary and not respond as carefully in the later rounds.

\section{Results and Discussion}

This four-survey-round Delphi study examined best practices for professional development identified by a panel of experts to meet online faculty needs and collected additional practices that the expert panel members believed to be relevant for preparing faculty to teach in the online classroom. The study received strong participation from the expert panel and the researcher believes that the strong participation rate can be attributed to the panel experts' interest in the results of the study to help them better understand and prepare faculty for teaching online at their institutions. The raw data yielded 41 best practices for professional development considerations, 16 organizational/institutional best practices, and 11 online classroom contextual best practices. For the professional development best practices, 33 were from the original survey and 8 were suggested by the expert panel. For the organizational/institutional best practices, eight were from the original survey round and eight were suggestions from the panel members. For the online 
classroom contextual best practices, eight were from the original survey and three were suggested by the panel members. However, it was determined that duplicate and similar items existed. After careful review, the duplicates were removed, resulting in a best practices framework for supporting online faculty with two categories: professional development considerations and institutional/organizational strategies. The group of online classroom contextual best practices were folded into the first two categories and clearly did not warrant a separate category. Table 4 provides best practices for professional development considerations and Table 5 provides best practices for institutional/organizational strategies for online faculty development.

After a final qualitative review process, the online faculty professional development topics considered essential were divided into four categories to structure the learning opportunities: faculty roles, online classroom design, learning processes, and legal issues. When thinking about faculty roles in the online classroom, key opportunities focus around faculty creating a presence in the online classroom, how to develop and maintain a teaching presence, strategies to manage an online classroom, and understanding faculty roles online. Additionally, the design of the online classroom is important and should include: how to plan, structure, and organize an online classroom, creating learning assessments appropriate for the learning environment, how to manage the online classroom, using the learning management system effectively in the learning process, and upholding quality standards online. Training for legal issues is increasingly becoming more necessary as the use of digital materials and intellectual property ownership can be misunderstood.

Although this study was focused on determining best practices for online faculty development, an impact still exists to the institution or organization. Best practices were identified that help to reinforce the importance of supports that should be provided to online faculty and programs. Three categories were identified through the review process: supportive campus climate, institution specific, and staffing support.

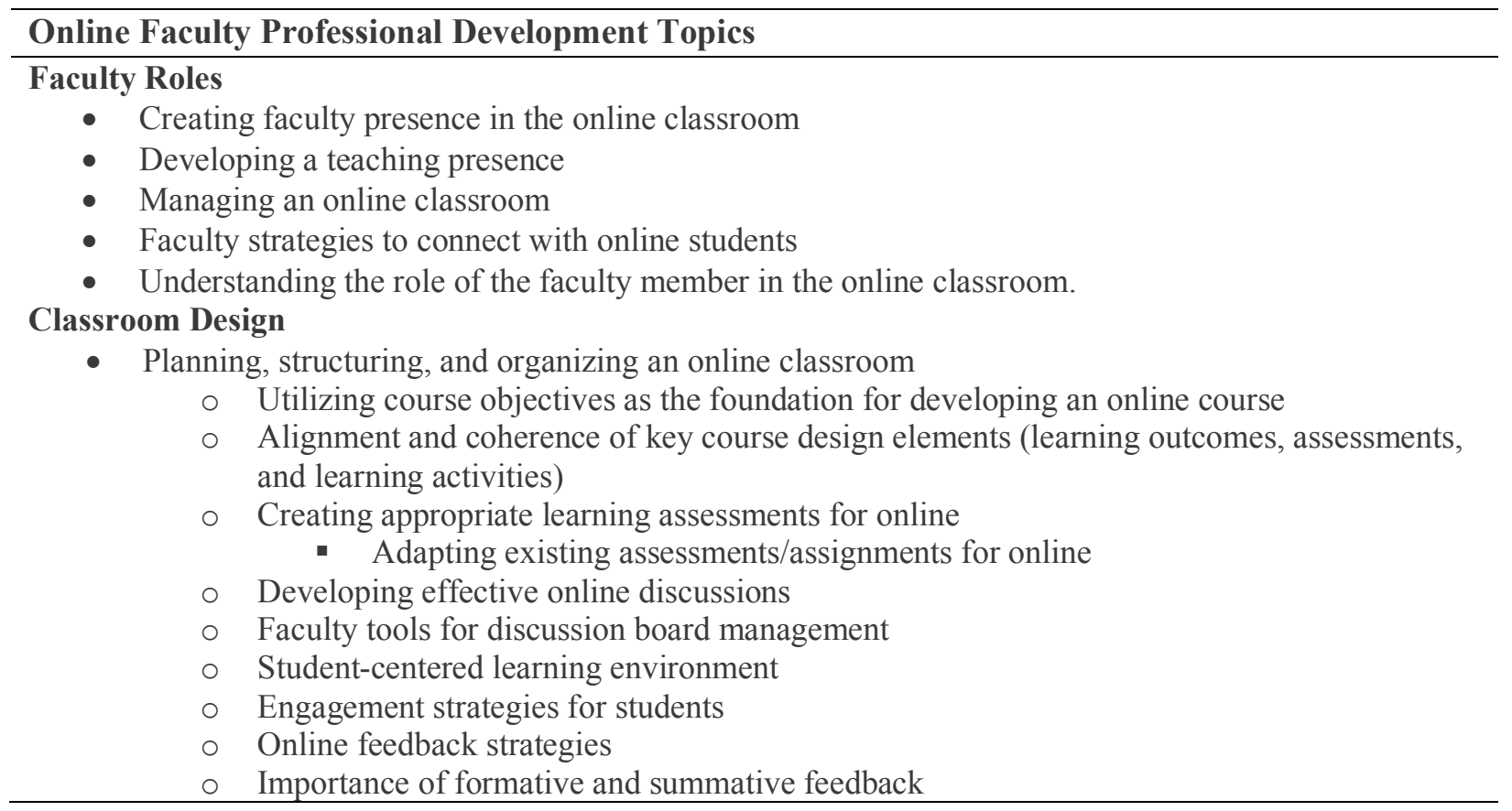

Table 4. Best Practices Framework for Online Faculty Support: Faculty Professional Development 
- Managing the online classroom

○ Utilizing the learning management system effectively

- Establishing a welcoming course environment

- Online communication strategies

$\circ \quad$ Guiding student learning

- Online discussion strategies

- Fostering online relationships and knowing students

- Assisting with online students with disabilities

- Online grading strategies

- Upholding quality standards online

- Course development standards and rubrics

- Purposeful use of technology and tools online

Learning Processes

- Preparation to develop the course

- Writing measurable course objectives

- Applying active learning strategies

- Adapting teaching pedagogy for the online classroom

Understanding Legal Issues in the Online Classroom

- Copyright compliance and fair use

- FERPA Guidelines

- ADA Compliance Guidelines

- Academic Integrity

Table 4 (cont.). Best Practices Framework for Online Faculty Support: Faculty Professional Development

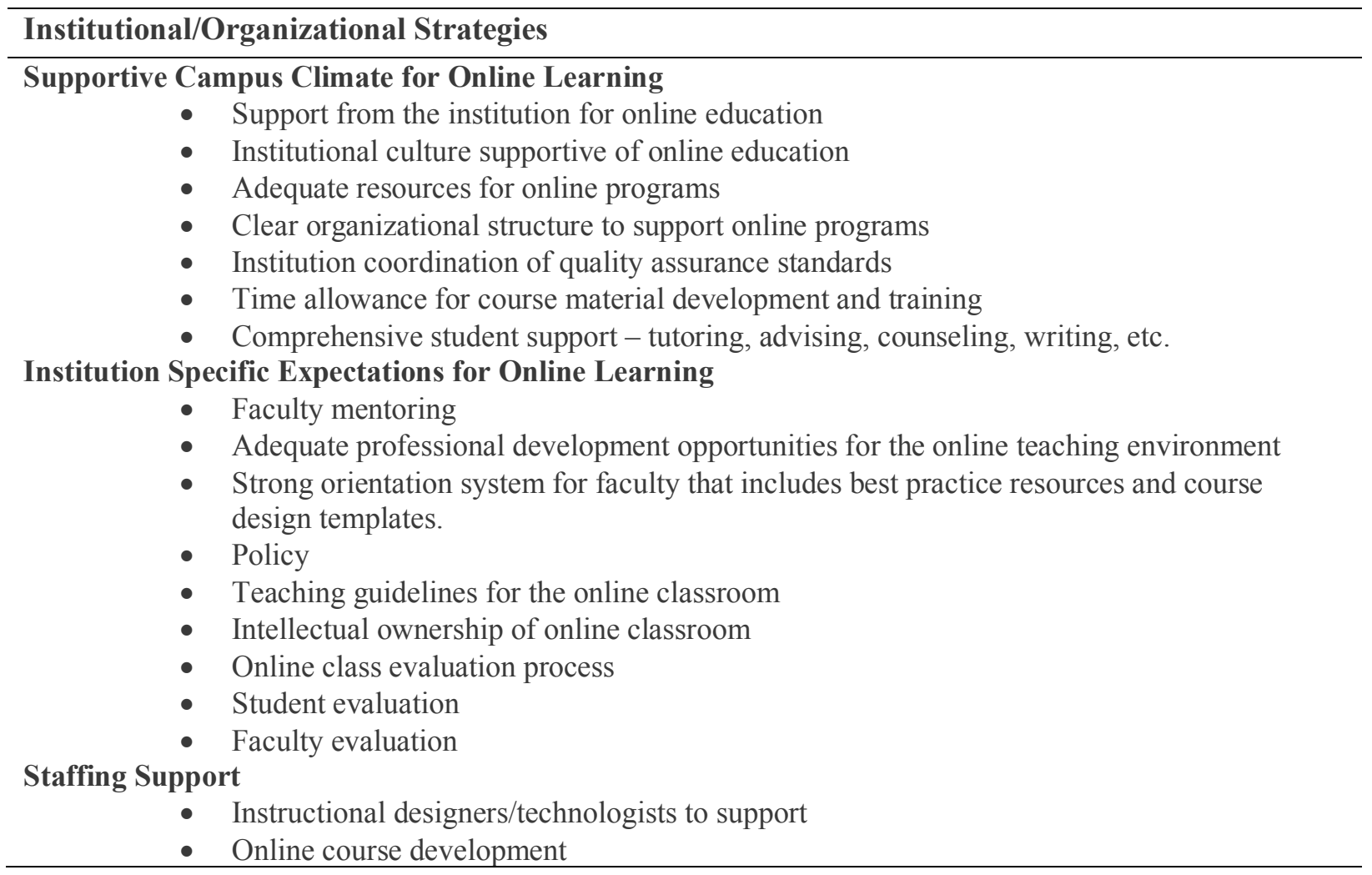

Table 5. Best Practices Framework for Online Faculty Support: Institutional/Organizational Strategies 




Table 5 (cont.). Best Practices Framework for Online Faculty Support: Institutional/Organizational Strategies

\section{Conclusions}

Institutions offer a variety of different professional development opportunities that typically focus on technology, pedagogy, and course content when preparing faculty to teach online (McQuiggan, 2007). Often faculty development models being provided are one size fits all models which might not meet the needs of faculty members preparing to teach online or who are currently teaching online (Rhode, Richter, \& Miller, 2017). Higher education institutions can use the resulting best practices to develop programs that help support and prepare faculty for the online environment.

As the popularity of online classes continues to grow, it is important for institutions to support faculty in ways that are conducive to their needs, and to create professional development programs that are tailored to the needs of online faculty members with the goal of influencing the faculty's effectiveness (Williams, Layne, \& Ice, 2014). Developing carefully thought-out and welldeveloped professional development programs may increase faculty loyalty and satisfaction (James \& Binder, 2012) and are key to the continued success of higher education (Elliott, 2014). Teaching and learning centers or those responsible for providing professional development should become responsive and proactive entities on campus to enable success with online programs through providing ongoing and varied professional learning opportunities for those at different career stages (Stockley, McDonald, \& Hoessler, 2015). The results of this Delphi study can be used help facilitate the development and design of professional development programs that meet the needs of online faculty members.

Rethinking approaches to faculty development around identified best practices can be a relevant and viable method to serve online faculty (Truong, Juillerat, \& Gin, 2016). Understanding the needs of online faculty is the first step to planning effective professional development. Given that online faculty members can be geographically dispersed, there is a need to connect them to the faculty community and professional development can help with skill development and community building. Institutional leaders need to build and foster a common vision around the role of online teaching that is passed along to the faculty and campus culture (Kaminskaya, 2006).

Using this research, a strategic plan can be developed for professional development instead of a randomly grouped collection of activities to encourage ongoing online faculty development (Baran \& Correia, 2014). Institutions should provide professional development that meets the 
perceived needs of online faculty, which can increase faculty's intrinsic motivation (Pink, 2011). The professional development should provide the tools faculty need to direct their classrooms, foster the urge to become better at teaching online, and demonstrate the need to improve student learning (Pink, 2011). Online faculty members need to feel that professional development is an ongoing part of their teaching responsibilities (Fabrice, 2010). When faculty members believe that there is strong organizational support around their needs, they tend to identify more with shared goals and become more involved in the process (Scott, Lemus, Knotts, \& Oh, 2016). In addition, it is important for institutions to provide faculty with positive learner-centered experiences that help them connect to the larger organizational culture so they learn to navigate their classrooms and organizations with success (Scott et al., 2016).

Offering professional development that meets online faculty needs will require a collaborative effort among all stakeholders in higher education (Carpenter, Sweet, \& Blythe, 2016). Using the essential elements of this research study, combined with the institutional knowledge around faculty and resources, can help personalize how these elements should be incorporated into professional development offerings. Additionally, findings from this study provide elements that could be used as a checklist to help certify faculty who are ready to serve as online instructional faculty and those who would be ready to serve as online course development faculty after successfully completing training.

Higher education organizations need to align goals of administration, faculty, and the institution to promote the success of online programs (Velez, 2015). In fact, Velez (2015) found institutions that create supportive environments between faculty and administration help to drive effectiveness within the organization. Developing faculty to teach online is a complex process that involves ongoing institutional commitment, time, and money (Barker, 2003). Each institution should work to create a culture for online learning that includes quality assurance standards, expectations for best practices, and training opportunities that prepare faculty for the online classroom. Additionally, having the organizational structure and support staff to design and work through important issues like ADA compliance, needs that are often different than the traditional face-to-face learning opportunities, support on using audio/visual resources, and library resources. Supporting online learning includes faculty support for instructional design, technology selection and usage, creating accessible materials, and evaluating courses and faculty instruction. To support continuous improvement, faculty need data about their online courses to help improve their teaching practice to help ensure that changes made in future course offerings are data driven (Reid, Sexton, \& Orsi, 2015).

\section{Recommendations for Future Research}

This study identified best practices for providing professional development for online faculty members through a teaching and learning center. This research does not provide evidencebased standards; each best practice should be further explored to determine impact and effectiveness. In addition, further research should be done on the order and timing of when the practices are delivered to online faculty members to help provide the best learning experiences for online students. The majority of these best practices have been suggested for the beginning of a faculty member's online teaching career. Additional research should be done to understand the needs of more experienced online faculty to assist their continued professional development as the online learning landscape continues to evolve (Crawford-Ferre \& Wiest, 2012). 


\section{References}

Allen, I. E., \& Seaman, J. (2016, February). Online report card-tracking online education in the United States. Babson Survey Research Group. Retrieved from http://onlinelearningsurvey.com/reports/onlinereportcard.pdf

Allen, I. E., \& Seaman, J. (2017). Digital learning compass: Distance education enrollment report 2017. Babson Survey Research Group, e-Literate, and WCET. Retrieved from http://digitallearningcompass.org

Alexiou-Ray, J., \& Bentley, C.C. (2015). Faculty professional development for quality online teaching. Online Journal of Distance Learning Administration, 18(4), 1-7. Retrieved from http://www.westga.edu/\%7Edistance/ojdla/winter184/ray bentley 184. html

Austin, A. E., \& Sorcinelli, M. D. (2013). The future of faculty development: Where are we going? New Directions for Teaching \& Learning, 2013(133), 85-97. doi:10.1002/t1.20048

Bailey, C. J., \& Card, K. A. (2009). Effective pedagogical practices for online teaching: Perception of experienced instructors. The Internet and Higher Education, 12(3), 152155. doi:10.1016/j.iheduc.2009.08.002

Baker, J., Lovell, K., \& Harris, N. (2006). How expert are the experts? An exploration of the concept of 'expert' within Delphi panel techniques. Nurse Researcher, 14(1), 59-70. doi:10.7748/nr2006.10.14.1.59.c6010

Baran, E., \& Correia, A. (2014). A professional development framework for online teaching. Techtrends: Linking Research and Practice to Improve Learning, 58(5), 95-101. doi:10.1007/s11528-014-0791-0

Baran, E., Correia, A. P., \& Thompson, A. (2011). Transforming online teaching practice: Critical analysis of the literature on the roles and competencies of online teachers. Distance Education, 32(3), 421-439. doi:10.1080/01587919.2011.610293

Barker, A. (2003). Faculty development for teaching online: Educational and technological issues. The Journal of Continuing Education in Nursing, 34(6), 273-278.

Birman, B. F., Desimone, L., Porter, A. C., \& Garet, M. S. (2000). Designing professional development that works. Educational Leadership, 57(8), 28-33.

Carpenter, R., Sweet, C., \& Blythe, H. (2016). The future of faculty development. Journal of Faculty Development, 30(2), 5-8.

Crawford-Ferre, H. G., \& Wiest, L. R. (2012). Effective online instruction in higher education. The Quarterly Review of Distance Education, 13(1), 11-14.

Creswell, J. W. (2014). Educational research: Planning, conducting, and evaluating quantitative and qualitative research ( $5^{\text {th }}$ ed.). Upper Saddle River, NJ: Pearson.

Dalkey, N., \& Helmer, O. (1963). An experimental application of the Delphi Method to the use of experts. Management Science, 9(3), 458-467. doi:10.1287/mnsc.9.3.458 
Delbecq, A. L., Van de Ven, A. H., \& Gustafson, D. H. (1975). Group techniques for program planning: A guide to nominal group and Delphi processes. Glenview, IL: Scott Foresman Company.

Eib, B., \& Miller, P. (2006). Faculty development as community building. International Review of Research in Open and Distance Learning, 3(2), 1-15. doi:10.19173/irrodl.v7i2.299

Elliott, R. (2014). Faculty development curriculum: What informs it. The Journal of Faculty Development, 28(3), 35-46.

Engleberg, I. N. (1991). Needs assessment: The first step in staff development. The Journal of Staff, Program, \& Organization Development, 9(4), 15-22.

Fabrice, H. (2010). Learning our lesson: Review of quality teaching in higher education. Paris, France: OECD.

Facer, K. (2011). Learning futures: Education, technology and social change. New York, NY: Taylor \& Francis.

Fish, W. W., \& Wickersham, L. E. (2009). Best practices for online instructors: Reminders. Quarterly Review of Distance Education, 10(3), 279-284.

Gabriel, M. A., \& Kaufield, K. J. (2008). Reciprocal mentorship: An effective support for online instructors. Mentoring and Tutoring: Partnership in Learning, 16(3), 311-327. doi:10.1080/13611260802233480

Hale, D. (2012). Online faculty development. In Maddix, M. A., Estep, J. R., \& Lowe, M. E. (Eds.). Best practices of online education: A guide for Christian higher education (pp 121-128). Charlotte, NC: Information Age.

Hasson, F., Keeney, S., \& McKenna, H. (2000). Research guidelines for the Delphi survey technique. Journal of Advanced Nursing, 32(4), 1008-1015. doi:10.1046/j.13652648.2000.t01-1-01567.x

Herman, J. H. (2012). Faculty development programs: The frequency and variety of professional development programs available to online instructors. Journal of Asynchronous Learning Networks, 16(5), 87-106. doi:10.24059/olj.v16i5.282

Jaggars, S. S., Edgecombe, N., \& Stacey, G. W. (2013). Creating an effective online instructor presence. Community College Research Center, Columbia University. Retrieved from: http://ccrc.tc.columbia.edu/media/k2/attachments/effective-online-instructor-presence.pdf

James, S. G., \& Binder, D. A. (2012). The care and feeding of part-time faculty: A model to retain community college adjuncts. National Forum of Educational Administration and Supervision Journal, 28(3), 2011-2012.

Kaminskaya, E. (2006). Teaching with technology: A case study of online faculty development at the University of Central Florida. Retrieved from International Research and Exchanges Board, University of Central Florida: http://www.irex.net/sites/default/files/kaminskaya.pdf 
Kerrick, S. A., Miller, K. H., \& Ziegler, C. (2015). Using continuous quality improvement (CQI) to sustain success in faculty development for online teaching. The Journal of Faculty Development, 29(1), 33-40.

Kreber, C., \& Kanuka, H. (2006). The scholarship of teaching and learning and the online classroom. Canadian Journal of University Continuing Education, 32(2), 109-131.

Kress, H., Thering, A., Lalonde, C., Kim, S., \& Cleeton, L. (2012). Faculty reflections on online course development and implementation for teacher education. International Journal of Technology, Knowledge \& Society, 8(1), 73-83. doi:10.18848/18323669/cgp/v08i01/56263

Lane, L. M. (2013). An open, online class to prepare faculty to teach online. Journal of Educators Online, 10(1), 1-32. doi:10.9743/jeo.2013.1.1

Likert, R. (1932). A technique for the measurement of attitudes. Archives of Psychology, $22(140), 1-55$.

Linstone, H. A., \& Turnoff, M. (1975). The Delphi Method: Techniques and applications. Reading, MA: Addison-Wesley.

Major, C. H. (2010). Do virtual professors dream of electric students? University faculty experiences with online distance education. Teacher College Record, 112(8), 2154-2208.

McQuiggan, C. A. (2011). Preparing to teach online as transformative faculty development (Doctoral dissertation). Available from ProQuest Dissertations and Theses database. (UMI No. 3471829)

Meskill, C., \& Anthony, N. (2007). Learning to orchestrate online instructional conversations: A case of faculty development for foreign language educators 1. Computer-Assisted Language Learning, 20(1), 5-19. doi:10.1080/09588220601118487

Moskal, P., Thompson, K., \& Futch, L. (2015). Enrollment, engagement, and satisfaction in the BlendKit faculty development open, online course. Online Learning, 19(4), 1-12. doi:10.24059/olj.v19i4.555

Murry, J. W., \& Hammons, J. O. (1995). Delphi: A versatile methodology for conducting qualitative research. The Review of Higher Education, 18(4), 423-436.

Natriello, G. (2005). Modest changes, revolutionary possibilities: Distance learning and the future of education. Teachers College Record, 107(8), 1885-1904. doi:10.1111/j.14679620.2005.00545.x

Otto, P. (2014). Librarians, libraries, and the scholarship of teaching and learning. New Directions for Teaching \& Learning, 2014(139), 77-93. doi:10.1002/tl.20106

Ouellett, M. (2010). Overview of faculty development: History and choices. In Gillespie, K. J. \& Robertson, D. L. (2010). A guide to faculty development (pp. 9-23). San Francisco, CA: Jossey-Bass. 
Pchenitchnaia, L. V. (2007). Essential and model programs for teaching and learning centers as reported by directors in selected research extensive universities: A Delphi study (Doctoral Dissertation). Available from ProQuest Dissertations and Theses database (UMI No. 3270379)

Peabody, D. (1962). Two components in bipolar scales: Direction and extremeness. Psychological Review, 69(2), 65-73.

Picciano, A. G. (2006). Blended learning: Implications for growth and access. Journal of Asynchronous Learning Networks, 10(3), 95-102.

Pink, D. H. (2011). Drive: The surprising truth about what motivates us. New York, NY: Penguin.

Reeves, D. B. (2012). Transforming professional development into student results. Alexandra, VA: ASCD.

Reid, L. F., Sexton, J., \& Orsi, R. (2015). Outcomes of a faculty development program promoting scholarly teaching and student engagement at a large research-intensive university. The Journal of Faculty Development, 29(3), 23-36.

Rhode, J., Richter, S. \& Miller, T. (2017). Designing personalized online teaching professional development through self-assessment. TechTrends, 61(5), 444-451. doi:10.1007/s11528017-0211-3

Rotondi, A., \& Gustafson, D. (1996). Theoretical, methodological and practical issues arising out of the Delphi Method. In M. Adler \& Ziglio, E. (Eds.), Gazing into the oracle: The Delphi Method and its application to social policy and public health (pp. 34-55). London: Jessica Kingsley Publishers.

Rowe, G., \& Wright, G. (1999). The Delphi technique as a forecasting tool: Issues and analysis. International Journal of Forecasting, 15(4), 353-375. doi:10.1016/s01692070(99)00018-7

Schmidt, S. W., Tschida, C. M., \& Hodge, E. M. (2016). How faculty learn to teach online: What administrators need to know. Online Journal of Distance Learning Administration, 19(1), $1-10$.

Scott, W., Lemus, D., Knotts, G., \& Oh, J. (2016). Why learner-centered new faculty orientations matter: Organizational culture and faculty retention. The Journal of Faculty Development, 30(1), 15-22.

Shelton, K., \& Saltsman, G. (2005). An administrator's guide to online education. Greenwich, CT: Information Age.

Shelton, K., Saltsman, G., Holstrom, L., \& Pedersen, K. (Eds.). (2014). Quality Scorecard 2014 handbook: Criteria for excellence in the administration of online programs. Newburyport, MA: Online Learning Consortium.

Skulmoski, G. J., Hartman, F. T., \& Krahn, J. (2007). The Delphi Method for graduate research. Journal of Information Technology Education, 6, 1-21. Retrieved from https://eric.ed.gov/?id=EJ807652 
Steinert, Y., Mann, K., Centeno, A., Dolmans, D., Spencer, J., Gelula, M., \& Prideaux, D. (2006). A systematic review of faculty development initiatives designed to improve teaching effectiveness in medical education: BEME Guide No. 8. Medical Teacher, 28(6), 497-526.

Stewart, C., Bachman, C., \& Johnson, R. (2010). Predictors of faculty acceptance of online education. Journal of Online Learning and Teaching, 6(3), 597-616.

Stockley, D., McDonald, J., \& Hoessler, C. (2015). Nudges, pulls, and serendipity: Multiple pathways to faculty development. The Journal of Faculty Development. 29(3), 61-68.

Tabor, S. W. (2007). Narrowing the distance. Quarterly Review of Distance Education, 8(1), $47-$ 57.

Truong, M. H., Juillerat, S., \& Gin, D. H. C. (2016), Good, fast, cheap: How centers of teaching and learning can capitalize in today's resource-constrained context. To Improve the Academy, 35(1), 180-195. doi:10.1002/tia2.20032

University Leadership Council. (2010). Engaging faculty in online education: Rightsizing incentives and optimizing support. Retrieved from https://www20.csueastbay.edu/oaa/files/student_success/EngFacOnlineEd.pdf

Vaill, A. L., \& Testori, P. A. (2012). Orientation, mentoring and ongoing support: A three-tiered approach to online faculty development. Journal of Asynchronous Learning Networks, 16(2), 111-119. doi:10.24059/olj.v16i2.256

Velez, E. (2015). Administration and faculty: How relationships create and solve the problems. Journal of Applied Learning Technology, 5(4), 37-40.

Wei, R. C., Darling-Hammond, L., Andree, A., Richardson, N., \& Orphanos, S. (2009). Professional learning in the learning profession. Dallas, TX: National Staff Development Council.

Wilhelm, W. J. (2001). Alchemy of the oracle: The Delphi technique. Delta Pi Epsilon Journal, 43(1), 6-26.

Williams, T., Layne, M., \& Ice, P. (2014). Online faculty perceptions on effective faculty mentoring: A qualitative study. Online Journal of Distance Learning Administration, 17(2), 1-19. Retrieved from http://www.westga.edu/ distance/ojdla/summer172/Williams Layne Ice172.html

Witkin, B. R. (1984). Assessing needs in educational and social programs. San Francisco, CA: Jossey-Bass. 